\title{
QT Dispersion as a Predictor of Coronary Lesion Severity in ST-Elevation Myocardial Infarction
}

\author{
Petrus S. Pinem ${ }^{\star 1}$, Cut A. Andra ${ }^{1}$, Ali N. Nasution ${ }^{1}$, \\ Harris Hasan ${ }^{1}$, Abdullah A. Siregar ${ }^{1}$, T. Bob Haykal ${ }^{1}$ \\ ${ }^{1}$ Department of Cardiology and Vascular Medicine, University of Sumatera Utara, \\ Adam Malik Hospital, Medan, Indonesia
}

\begin{abstract}
Background: The prolonged QT interval and QT dispersion are ECG markers associated with the incidence of ventricular arrhythmias, and cardiovascular mortality in patients with acute myocardial infarction. This study aims to examine whether QT dispersion can be used as a predictor of the severity of lesions in STEMI patients in Haji Adam Malik General Hospital. Methods: A total of 68 patients with STEMI who undergo coronary angiography at Haji Adam Malik General Hospital since Januari 2018 until December 2018 were recruited in this cross sectional study. QT dispersion was counted from the first ECG when patient admitted at the emergency room. And then coronary angiography was done, and the Gensini score was calculated as a parameter of coronary lesion severity.Results: In the ROC curve analysis, the cut-off value of QT dispersion in the prediction of severe coronary lesion was 80.5 (AUC 0.874 , 95\% CI $0.778-0.970$, $\mathrm{p}<0.001$ ). The STEMI group with QT dispersion $\geq 80.5$ had a higher incidence of severe coronary lesion than the group with QT dispersion < 80.5 of 34 people (89.5\%) versus 4 people $(10.5 \%)$. QT dispersion $\geq 80.5$ is considered to predict the severity of coronary lesion with a sensitivity of $89.5 \%$, a specificity of $83.3 \%$, a negative predictive value (NPV) of $86.2 \%$ and a positive predictive value (PPV) of $87.1 \%$. Conclusion: QT dispersion is a simple, very useful and an inexpensive indicator which may be used as a predictor for coronary lesion severity in patients with STEMI.
\end{abstract}

Keywords: QT dispersion, Gensini Score, STEMI.

\section{Introduction}

Acute myocardial infarction (IMA) is a condition that describes the occurrence of necrosis of the heart muscle due to narrowing of the heart arteries. In acute myocardial infarction there is a disruption of blood flow to the heart which causes heart muscle cells to experience hypoxia. The coronary blood vessels are blocked so that the blood flow to the heart muscle stops, unless there is a small amount of collateral flow from the surrounding blood vessels. Muscle areas that do not get blood flow at all or have very little flow so they cannot maintain the function of the heart muscle and are said to experience infarction. ${ }^{1,2}$

Petrus S. Pinem et al /International Journal of PharmTech Research, 2019,12(2): 111-118.

DOI: http://dx.doi.org/10.20902/IJPTR.2019.120203 
The main characteristics of acute myocardial infarction in ST segment elevation are typical angina and ECG changes with elevation images. An ECG is an important dignostic tool in establishing a diagnosis of STEMI. In this situation an increase in ST segment will be found within a few hours after chest pain is felt. Assessment of ST elevation was carried out at J point and found in 2 contiguous leads. ${ }^{3,4}$

The QT interval on the ECG illustrates summation of potential differences during ventricular depolarization and repolarization. The prolongation of the QT interval is thought to be the cause of ventricular arrhythmias, possibly due to the restoration of non-uniform ventricular excitability in the state of regional differences from the sympathetic system in the disturbed myocardial region. ${ }^{5,6,7}$

In patients with acute myocardial infarction there is a disturbance of ventricular repolarization, the formation of heterogeneity in ventricular repolarization associated with the formation of QT dispersion on the ECG. QT dispersion has implications for the occurrence of ventricular arrhythmias and is associated with poor prognostics in patients with myocardial infarction. Research by Yuniadi (2005) also shows that QT dispersion can be used as a simple tool to predict the incidence of ventricular tachyarrhythmias and / or sudden cardiac death after infarction. ${ }^{8,9,10}$

QT dispersion is also considered to have a relationship with the extent of coronary lesions in patients with coronary heart disease. From a study by Yilmaz in 2006, it was found that QT dispersion was related to the severity of coronary lesions in patients with coronary heart disease. Then in 2016 Helmy found that QT dispersion was related to the severity of coronary lesions in patients with acute myocardial infarction with STsegment elevation (STEMI). However, this study was conducted in patients with acute myocardial infarction with ST-segment elevation without a history of diabetes mellitus. However, the relationship between QT dispersion and the severity of atherosclerosis in patients with acute myocardial infarction with ST-segment elevation cannot be determined. This study aim to determine whether the QT dispersion can be used as a predictor of coronary lesion severity in patients with STEMI. ${ }^{11,12}$

\section{Method}

\section{Study Design}

This study is a cross-sectional study conducted at the Haji Adam Malik Hospital in Medan with permission from the Research Ethics Committee of the Faculty of Medicine, University of North SumatraHaji Adam Malik Hospital. The study subjects taken from January to December 2018 were patients with a diagnosis of STEMI based on diagnosis criteria from ESC. The inclusion criteria were patients with a diagnosis of acute myocardial infarction with ST segment elevation who came to the Haji Adam Malik General Hospital with sinus rhythm without a history of coronary artery bypass graft (CABG) or percutaneous coronary intervention (PCI) action, cardiomyopathy, valvular heart disease or congenital heart disease that did not have a history of drug use that can interfere with the QT interval such as amiodarone, digitalis, beta blockers, and calcium antagonists before an ECG examination. Patients with electrolyte balance disorders, cerebrovascular disease, and kidney disorders (serum creatinine> $2.0 \mathrm{mg}$ ) will be excluded from this study. A 12-lead ECG examination was carried out at the beginning of the admission of the emergency unit with a recording speed of $25 \mathrm{~mm} / \mathrm{s}$ and a scale of $10 \mathrm{~mm} / \mathrm{mv}$. The number of patient samples in this study were 62 people and had fulfilled the inclusion and exclusion criteria so that they could be included in the study.

\section{Study Procedure}

Data on clinical and demographic characteristics including age, sex, previous history of disease such as diabetes mellitus, hypertension, smoking history, and family history of CHD, and a complete history of drug use were recorded. The initial important data evaluated were 12 lead ECG at the beginning of the admisson into the emergency unit. From the ECG the duration of QT dispersion will be assessed, then coronary angiography are performed and followd by percutaneous coronary intervention if suitable. The Gensini score was then assessed from the results of angiography. Then based on the Gensini score, the subjects will be divided into two groups, he first group with a high score $>20$ and the second group with a score of low $\leq 20$. 


\section{Statistical analysis}

Processing and analysis of statistical data using computer statistical tools with SPSS software. Categorical variables are presented by number or frequency (n) and percentage (\%). Numerical variables are presented with mean values with standard deviations for normally distributed data. Test the normality of numerical variables in all research subjects using the Kolmogorov-Smirnov test with $\mathrm{n}>50$. Comparisons between the two groups on categorical independent variables and numerical dependent variables were performed by unpaired T-test. If the unpaired T-test requirements are not met, then the Mann-Whitney test is used.

For samples that were found to be significant in the bivariate analysis test, they were included in the multivariate test. Variables found to have significance values $\mathrm{p}<0.05$ in multivariate analysis are displayed in the form of Odds Ratio (RO) with $95 \%$ confidence intervals.

\section{Results}

\section{Baseline Characteristics}

The study subjects were divided into two groups, the group with Gensini score $\leq 20$ (30 people, $44 \%$ ) and the group with Gensini score $>20$ (38 people, 54\%). Of the 30 people with Gensini score $\leq 20$ consisted of 29 people $(91.7 \%)$ men and 1 person $(8.3 \%)$ women. Whereas in the group with Gensini score> 20 consisted of 25 people (65.8\%) men and 13 people (34.2\%) women. The mean age of the study subjects differed significantly between the two groups, where the mean age of subjects in the group with Gensini score $\leq 20$ was 51 years, while the average age in the group with a Gensini score $>20$ was 57 years $(p=0.012)$.

From the clinical parameters, systolic blood pressure (TDS) there was also a statistically significant difference $(p=0.041)$ where the median blood pressure in the group with a Gensini score $\leq 20$ was $115 \mathrm{mmHg}$ whereas in the group with a Gensini score > 20 was $130 \mathrm{mmHg}$. However, there was no statistically significant difference in heart rate between the two groups ( $p>0.05$ ).

Table 1. Baseline Characteristics

\begin{tabular}{|llll|}
\hline Parameter & $\begin{array}{l}\text { Gensini Score } \\
(\mathbf{n = 3 0})\end{array}$ & $\begin{array}{l}\text { Gensini Score }>\mathbf{2 0} \\
(\mathbf{n = 3 8})\end{array}$ & p value \\
\hline Age & $51.6 \pm 10.21$ & $57.7 \pm 9.31$ & $0.012^{*}$ \\
\hline Sex (Female) & $1(3.3 \%)$ & $13(34.2 \%)$ & $0.002^{*}$ \\
\hline Systolic Blood Pressure (mmHg) & $115(80-150)$ & $130(90-160)$ & $0,041^{*}$ \\
\hline Heart Rate (bpm) & $79(50-138)$ & $79(60-122)$ & 0.743 \\
\hline Risk Factor & & & \\
$\quad-\quad$ Hipertension & $19(43.3 \%)$ & $2(5.3 \%)$ & 0.359 \\
$\quad-\quad$ Diabetes mellitus & $4(13.3 \%)$ & $31(81.6 \%)$ & $<0.001^{*}$ \\
$-\quad$ Smoking & $26(86.7 \%)$ & $26(68.4 \%)$ & 0.078 \\
$\quad$ Family History & $13(43.4 \%)$ & $2(5.3)$ & $<0.001^{*}$ \\
\hline Leucocyte $\left(10^{3} /\right.$ uL \pm SD) & $14.861 \pm 3105.92$ & $14.459 .2 \pm 3269.17$ & 0.608 \\
\hline Ureum & $22.5(13-83)$ & $26.0(12-90)$ & 0.710 \\
\hline Creatinin & $0.9(0.5-1.6)$ & $0.8(0.5-1.5)$ & 0.516 \\
\hline Blood Glucose & $133(62-387)$ & $143.5(88-559)$ & $0.047 *$ \\
\hline Onset & $15.0(2.0-96.0)$ & $24.0(1.0-144)$ & 0.097 \\
\hline TIMI Risk & $3.0(1.0-14.0)$ & $4.0(2.0-9.0)$ & 0.121 \\
\hline Ejection Fraction & $52.0(42.0-58.0)$ & $54.0(42.0-58.0)$ & 0.244 \\
\hline KILLIP & & & 0.194 \\
$-\quad$ I & $25(83.3 \%)$ & $27(71.1 \%)$ & \\
$-\quad$ II & $3(10.0 \%)$ & $10(26.3 \%)$ & \\
$-\quad$ III & $0(0 \%)$ & $0(0 \%)$ & \\
$-\quad$ IV & $2(6.7 \%)$ & $1(2.6 \%)$ & \\
\hline
\end{tabular}




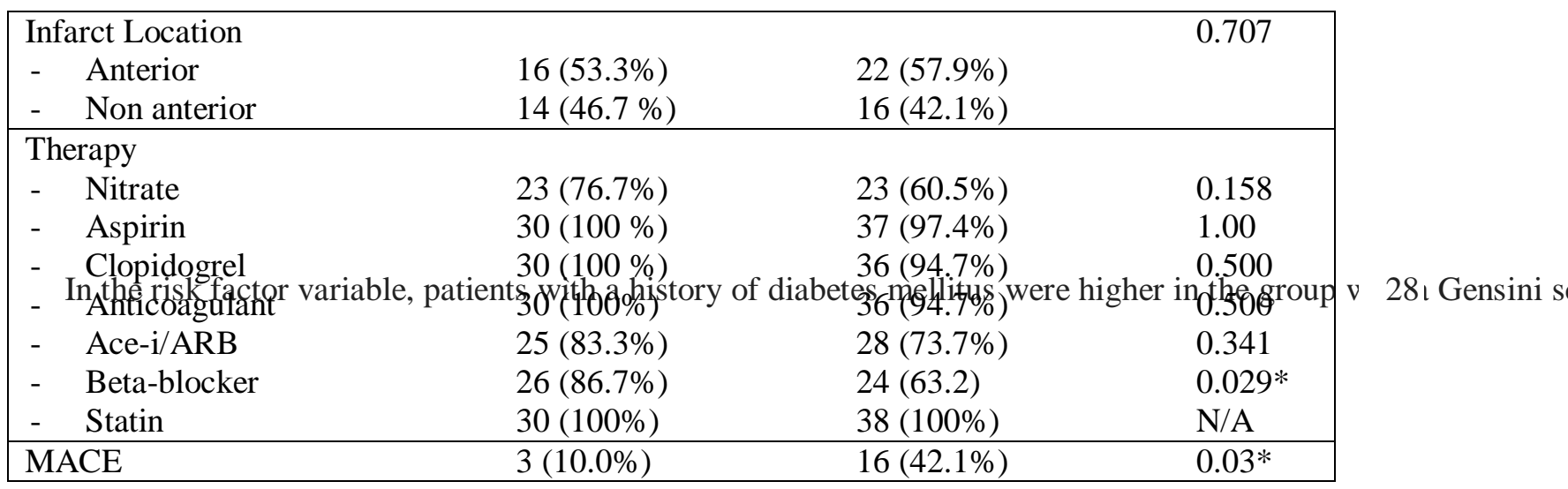

people $(73.7 \%)$ compared to 19 people $(63.3 \%)$ in the group with Gensini score $\leq 20$ but this did not differ statistically significant $(\mathrm{p}=0.359)$. Smoking rates were found to be higher in the group with Gensini score $\leq$ 20 of 26 people (86.7\%) whereas in the group with Gensini score $>20$ there were 26 people $(68.4 \%)$ but this was also not statistically significant $(\mathrm{p}=0.078)$.

In the blood laboratory examination it was found that the average leukocyte score was $14861 \pm$ 3105 in the group with Gensini score $\leq 20$ and $14.459 \pm 3269$ in the group with Gensini score $>20$. This was not statistically significant with a value of $\mathrm{p}=0.608$. On laboratory examination it was also found that mean blood glucose level is $133(62-387) \mathrm{mg} / \mathrm{dl}$ in the group with Gensini score $\leq 20$ and $143.5(88-559) \mathrm{mg} / \mathrm{dl}$ in the group with a Gensini score $>20$, this difference was statistically significant with a p-value $=0.047$. The ejection fraction between the two groups was also not significantly different.

In the group with a Gensini score $\leq 20$ as many as 16 people $(53.3 \%)$ were found to have an infarction location anteriorly compared to a group with a Gensini score > 20 as many as 22 people (57.9\%). Whereas for non-anterior locations in the group with Gensini score $\leq 20$ it was found in 14 people (46.7\%) and in the group with Gensini score > 20 as many as 16 people (42.1\%). Whereas for the onset of events, TIMI risk and Killip classes, there was no statistically significant difference in the two groups with a value of p> 0.05. Major cardiovascular events (MACE) were significantly higher in the group with gensini score $>20$ as many as 16 people (42.1\%) compared to the group with Gensini score $\leq 20$ as many as 3 people (10.0\%), with $\mathrm{p}$ values $=0.03$

\section{Relationship QT dispersion with the severity of lesions in STEMI Patients}

In this study, the average QT dispersion in the group with Gensini score> 20 was 92 (75-123) msec and in the group with Gensini score $\leq 20$ was 75 (69-107) msec. QT dispersion in both groups was found to be significantly different with $\mathrm{p}<0.001$ (Table).

Table 2. Correlation of QT dispersion with Gensini Score in STEMI

\begin{tabular}{|c|c|c|c|c|}
\hline & \multicolumn{2}{|c|}{ Gensini Score } & \multirow[t]{2}{*}{$\mathrm{Z}$} & \multirow[t]{2}{*}{$\mathrm{P}$} \\
\hline & $\leq 20$ & $>20$ & & \\
\hline $\begin{array}{ll}\text { Median } & \text { QT } \\
\text { dispersion } & \end{array}$ & $75(69-107)$ & $92(75-123)$ & -5.295 & $<0.001$ \\
\hline
\end{tabular}

\section{QT Dispersion Cut Point Value With Degree Of Lesion Severity In STEMI Patients}

Using the ROC curve, Area Under the Curve (AUC) can be assessed from QT dispersion parameters, which will show QT dispersion ability as a predictor of the severity of coronary lesions in patients with STEMI. In this study, AUC 0.875 was found with $\mathrm{p}$ value $<0.001$. This shows that QT dispersion is clinically significant as a predictor of the severity of coronary lesions of patients with STEMI. The cut-off value was found to be> 80.5 which is considered to predict the severity of the lesion with sensitivity of $89.5 \%$ and specificity of $83.3 \%$. 


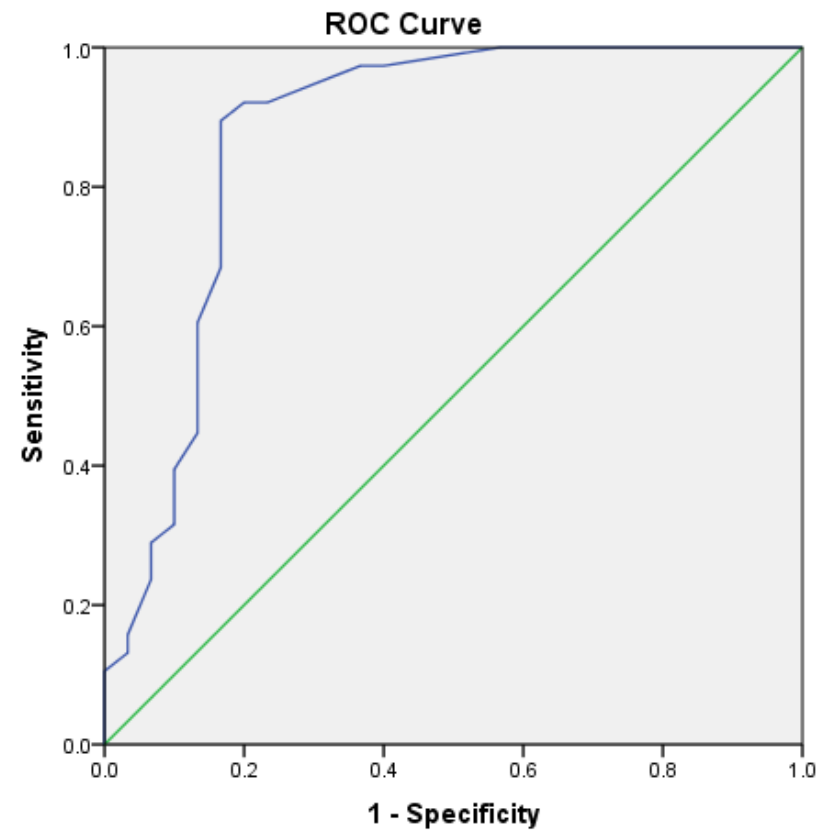

Figure 1. ROC Curve of QT Dispersion as a Predictor of Coronary Lesion Severity

Table 3. QT dispersion test results based on ROC

\begin{tabular}{lccccc}
\hline Cut-Off Points & Sens & Spes & AUC & p value & 95\% CI \\
\hline$\geq 80.5$ & & & & & \\
\hline
\end{tabular}

\section{QT Diagnostic Dispersion Test Analysis Severity of Coronary Lesions in STEMI Patients}

In 68 study subjects, we found 39 people had QT dispersions $\geq 80.5 \mathrm{msec}$ and 29 people had QT dispersion $<80.5 \mathrm{msec}$. The study subjects in the QT dispersion group $\geq 80.5$ had a Gensini score of $>20$ which was 34 people $(89.5 \%)$ compared to 5 people $(16.7 \%)$ who had a Gensini score $\leq 20$. Whereas in the dispersion group QT $<80.5 \mathrm{msec}$ had a Gensini score $<20$ as many as 25 people (83.3\%) compared to 4 people $(10.5 \%)$ who had a Gensini score $\leq 20$.

QT dispersion $\geq 80.5 \mathrm{msec}$ can predict coronary lesion severity in STEMI patients with a sensitivity of $81.6 \%$, specificity $80.0 \%$, Negative Predictive Value (NPV) $77.1 \%$ and Positive Predictive Value (PPV) $90.9 \%$.

\section{Analysis of Factors Affecting the Degree of Coronary Lesion Severity of STEMI Patients}

Based on the results of the bivariate analysis of parameters related to the severity of coronary lesions, it was found that age, male sex, systolic blood pressure at admission, history of diabetes mellitus, family history, blood sugar levels at the time of pregnancy, and age had a statistically significant relationship. Of all these parameters, gender, family history, history of DM and QT dispersion which had the highest Odds Ratio (Table 4). 
Table 4. Bivariate Analysis Factors - Factors Affecting Affect the Degree of Severity of Lesions

\begin{tabular}{llll}
\hline Parameter & OR & $\mathbf{9 5 \%}$ CI & P value \\
\hline Age (> 55 years) & 0.31 & $0.507-19.985$ & 0.566 \\
\hline Sex (Female) & 15.080 & $1.841-123.53$ & $0.002^{*}$ \\
\hline Systolic blood pressure $(>140 \mathrm{mmHg})$ & 4.5 & $1.422-14.242$ & $0.010^{*}$ \\
\hline Diabetes Mellitus History & 31.259 & $0.031-0.300$ & $<0.001^{*}$ \\
\hline Family History & 13.765 & $2.789-67.9$ & $<0.001^{*}$ \\
\hline Blood glucose level $(>125 \mathrm{mg} / \mathrm{dl})$ & 0.700 & $0.222-2.210$ & 0.579 \\
\hline QT dispersion $(>80.5 \mathrm{msec})$ & 42.50 & $10.35-174.523$ & $<0.001^{*}$ \\
\hline
\end{tabular}

The researcher then wanted to find out more that the dispersion of QT> $80.5 \mathrm{msec}$ could be used as a predictor to predict the severity of coronary lesions in STEMI patients. For this reason, researchers must first carry out bivariate analysis of other factors that can affect the severity of the lesion. Then the results of this bivariate analysis will be continued into multivariate analysis.

Multivariate analysis in this study is used to determine which independent variables are the most dominant and affect the severity of coronary lesions in STEMI patients. So multivariate analysis was carried out to determine the factors that could be used as predictors of the severity of coronary lesions in STEMI patients. From the 6 steps of multivariate analysis using logistic regression involving several clinical parameters in this study, it shows that there are 2 independent factors that can predict the severity of coronary lesions, namely history of DM [OR 13,789 $(2.09-90,695), \mathrm{p}=0.006]$ and QT dispersion [ OR 17,631 $(3,081$ $100,905), \mathrm{p}=0,001]$ (Table 5).

Table 5. Independent Factors as Predictor of Coronary Lesion in STEMI

\begin{tabular}{lcccc}
\hline Parameter & P value & OR & Lower & Upper \\
\hline Diabetes Mellitus History & 0.006 & 17.631 & 3.081 & 100.905 \\
QT Dispersion & 0.001 & 13.789 & 2.096 & 90.695 \\
\hline
\end{tabular}

\section{Discussion}

In patients with acute myocardial infarction there is a disturbance of ventricular repolarization, namely the formation of heterogeneity in ventricular repolarization associated with the formation of QT dispersion on the ECG. QT dispersion has implications for the occurrence of ventricular arrhythmias and is associated with poor prognostics in patients with myocardial infarction. In addition, QT dispersion also has a relationship with the severity of lesions in patients with STEMI. ${ }^{8,9,12}$

This study produces characteristic data and analysis of research subjects who can provide information, support, or refute theories that have been suggested from previous studies regarding the relationship of QT dispersion to the severity of lesions in STEMI patients. The total number of subjects in this study were 68 people consisting of groups with Gensini scores $\leq 20$ (30 people, $44 \%$ ) and groups with Gensini scores> 20 (56 people, $45 \%)$.

Baseline characteristics of the study between the two groups showed no significant differences in sex and heart rate, but significant differences were found in age and blood pressure. And in groups with a worse severity of lesions patients were found to have a higher risk factor for diabetes mellitus than those who experienced successful reperfusion. While other risk factors such as hypertension, smoking, and family history did not differ significantly between the two groups. Where it is known that diabetes mellitus is a risk factor for the occurrence of multiple coronary lesions that will worsen the severity of the lesion. Laboratory parameters showed no significant differences in leukocyte, urea and creatinine values in both groups. 
However, there were significant differences in the current KGD values between the two groups. Likewise with the onset of events, TIMI risk and the KILLIP class were also not significantly different between the two groups. Then, when patients are hospitalized, there is no significant difference in therapy between the two groups. Treatment and MACE between the two groups were also not significantly different. ${ }^{13,14,15}$

In this study, the average QT dispersion in the group with more severe lesion severity was 92 (75123) msec and in the group with a lower severity, the lesion was $75(69-107) \mathrm{msec}$. QT dispersion in both groups was found to be significantly different. This is in accordance with the research conducted by Yilmaz in 2006 and Helmy in 2016. ${ }^{11,12}$

Significant QT dispersion point values to predict lesion severity were obtained through the ROC curve. The dispersion value of QT $\geq 80.5 \mathrm{msec}$ is considered to be the optimal value in predicting the severity of lesions based on the ROC curve with a sensitivity of $81.6 \%$ and specificity of $80 \%$. The subjects in the QT dispersion group $\geq 80.5 \mathrm{msec}$ had a worse lesion severity compared to the QT dispersion group $<80.5 \mathrm{msec}$ which was 27 people (90\%) compared to 3 people (10\%). This is in line with previous research by Helmy in 2016. Where it is known that in patients with acute myocardial infarction there is a disruption of ventricular repolarization namely the formation of heterogeneity in ventricular repolarization associated with the formation of QT dispersion on the ECG. QT dispersion has implications for the occurrence of ventricular arrhythmias and is associated with poor prognostics in patients with myocardial infarction. ${ }^{8,9,12}$

DM history can also be a predictor of the degree of severity of the lesion. In this study it was found that the history of DM was one of the independent factors that could predict the severity of coronary lesions in patients with STEMI [OR 13,789 $(2.09-90,695), \mathrm{p}=0.006$ ]. This is consistent with previous studies by Hegde et al. in 2014 which found that patients with DM were more likely to experience multiple coronary lesions than patients without DM. ${ }^{16}$

\section{Study Limitations}

In addition, the number of samples in this study is smaller than the previous studies and only carried out in one place of research so that further research needs to be conducted with a larger sample size and collaboration with several referral hospitals that have intensive cardiovascular facilities in order to provide more representative results

\section{Conclusion}

This study found that the QT dispersion value could be used as a predictor of the severity of coronary lesions in STEMI patients, where the cut-off value obtained from this study was $\geq 80.5 \mathrm{msec}$.

\section{References}

1. Bender JR, Russel KS, Rosenfeld LE, et al. Coronary Artery Disease, Oxford American Handbook of Cardiology. New York: Oxford University Press; 2011.

2. Rhee JW, Sabatine MS, Lilly LS. 'Acute coronary syndrome' in: Lilly LS (ed.) Pathophysiology of Heart Disease: A Collaborative Project of Medical Students and Faculty, 5th edition 2015. Baltimore: Lippincott of Williams and Wilkins

3. Perhimpunan Dokter Spesialis Kardiovaskular Indonesia. Pedoman Tatalaksana Sindrom Koroner Akut. Jakarta: Centra Communication, 2015

4. Thygesen, K, Alpert JS, Jaffe AS, and et al. "Third universal definition of myocardial infarction." Circulation, 2012: 126:2020-2035.

5. Vassallo, JA, Cassidy DM, Kindwall E, Marchlinski FE, and Josephson ME. "Nonuniform recovery of excitability in the left ventricle." Circulation, 1988: 78:1365-1372, doi:10.1161/01.CIR.78.6.1365.

6. Abildskov, JA. "The sympathetic imbalance hypothesis of the QT interval." Journal of Cardiovascular Electrophysiology, 1991: 2:355-359, doi:10.1111/j.1540-8167.1991.tb01332.x.

7. Surawicz, B, and Knoebel SB. "Long QT: good, bad, or indifferent:." Journal of the American College of Cardiology, 1984: 4:398-413, doi:10.1016/S0735-1097(84)80232-6.

8. Zareba, W, Moss AJ, and Le Cessie S. "Dispersion of ventricular repolarization and arrhytmic cardiac death in coronary artery disease." American Journal Cardiology, 1994: 74:550-553, doi:10.1016/0002-9149(94)90742-0. 
9. Lee, KW, Okin PM, Kligfield P, Stein KM, and Lerman BB. "Precordial QT dispersion and inducible ventricular tachycardia." American Heart Journal, 1997: 134:1005-1013, doi:10.1016/S00028703(97)70019-X.

10. Yuniadi, Y, Munawar M, Setianto B, and Rachman Otte J. "QT dipersion, a simple tool to predict ventricular tachyarrhytmias and/or sudden cardiac death after myocardial infarction." Medical Journal of Indonesia, 2005: 14:230-6, doi:10.13181/mji.v14i4.201.

11. Yilmaz, R., Demirbag, R., Gur, M. "The association of QT dispersion and QT Dispersion Ratio with Extent and severity of coronary artery disease". ANE, 2006: 11(1):43-51, doi:10.1111/j.1542474X.2006.00081.x.

12. Helmy, H. et al. Correlation of corrected QT dispersion with the severity of coronary artery disease detected by SYNTAX score in non-diabetic patients with STEMI. Egyptian Society of Cardiology. 2016: 1110-2608, doi:10.1016/j.ehj.2016.12.001.

13. Goldberger, AL. Clinical Electrocardiography: A Simplified Approach. Edisi 7. St.Louis: CV Mosby, 2006.

14. Conroy RM, Pyorala K, Fitzgerald AP, et al. Estimation of ten-year risk of fatal cardiovascular disease in Europe: the SCORE project. European Heart Journal, 2003; 24:987-1003, doi:10.1016/S0195-668X(03)00114-3.

15. Jimenez-Candil J, et al. "In-hospital prognosis in non-ST-segment elevation acute coronary syndrome derived using a new risk score based on electrocardiographic parameters obtained at admission." Revista Española de Cardiología. 2010; 63(7): 851-5

16. Hedge, S., Mallesh, P. Yeji, SM., Gadad, VM., Punja, G. Comparative Angiographic Profile in Diabetic and Non-Diabetic Patients with Acute Coronary Syndrome. Journal of Clinical and Diagnostic Research. 2014:MC07-MC10. 